\title{
Temperature-dependent inelastic response of passivated copper films: Experiments, analyses, and implications
}

\author{
Y.-L. Shen ${ }^{\text {a) }}$ \\ Department of Mechanical Engineering, University of New Mexico, Albuquerque, New Mexico 87131 \\ U. Ramamurty \\ Department of Metallurgy, Indian Institute of Science, Bangalore-560 012, India
}

\begin{abstract}
The temperature-dependent mechanical behavior of passivated copper films is studied. Stresses in copper films of thickness ranging from 40 to $1000 \mathrm{~nm}$, deposited on quartz or silicon substrates and passivated with silicon oxide were measured by using the substrate curvature method. The thermal cycling spans a temperature range from -196 to $600^{\circ} \mathrm{C}$. It was observed that the passivated films do not exhibit a significant stress relaxation at high temperatures that is typically found in unpassivated films. The measured mechanical behavior was found to be rate insensitive within the heating/cooling rate range of $5-25^{\circ} \mathrm{C} / \mathrm{min}$. Furthermore, a significant strain hardening during the course of thermal cycling was noted. Analyses employing continuum plasticity show that the experimentally measured stress-temperature response can only be rationalized with a kinematic hardening model. Analytical procedures for extracting the constitutive properties of the films that were developed on the basis of such model are presented. To emphasize the importance of the appropriate choice of constitutive model, results of finite element modeling for predicting thermal stresses in copper interconnects are presented. The modeling assumed parallel copper lines embedded within the combined low $k$ /oxide dielectric materials. It was found that ignoring plastic strain hardening of copper can lead to significant errors in the stress and strain developed in the interconnect.
\end{abstract}

\section{INTRODUCTION}

The progressive replacement of copper $(\mathrm{Cu})$ in place of aluminum ( $\mathrm{Al}$ ) for interconnect metallization in integrated circuits has necessitated the need for understanding the thermomechanical behavior of thin $\mathrm{Cu}$ films. Considerable progress has been made in recent years. ${ }^{1-12}$ Passivated $\mathrm{Cu}$ films behave significantly differently from their unpassivated counterparts. Thermal mismatch induced stresses in passivated $\mathrm{Cu}$ films do not relax significantly at elevated temperatures during thermal cycling. ${ }^{1,2,5,8}$ This has been attributed to the prevention of surface atomic diffusion from relaxing the film stress and to the constrained dislocation motion due to the passivation. (In the case of $\mathrm{Al}$, even the unpassivated film is naturally coated with a thin native oxide layer.) The overall stress-temperature response of $\mathrm{Cu}$ films, from which the constitutive behavior of the film can be extracted is, therefore, highly influenced by the passivation. As a result, great care has to be exercised in selecting the constitutive model for simulating the thermomechanical behavior of the $\mathrm{Cu}$ films.

The objective of the present study is to develop a detailed understanding of the mechanical behavior of passivated $\mathrm{Cu}$ films, in particular, the temperature-dependent elastic-plastic response within the continuum framework. For this purpose, temperature excursion experiments on $\mathrm{Cu}$ films of varying thickness, sandwiched between a substrate and a thin passivation layer, were conducted and analyzed. Special attention

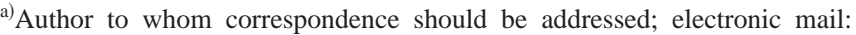
shenyl@me.unm.edu
}

is given to the plastic hardening characteristics during cyclic loading. The constitutive response extracted from the film experiment is used for numerical modeling of thermal stresses in a model interconnect structure with the objective of illustrating the importance of choosing appropriate material models in predicting the thermal stresses in $\mathrm{Cu}$ interconnects.

\section{EXPERIMENT}

The experiments were performed with electron beam deposited films on quartz substrates. The $\mathrm{Cu}$ films with thicknesses of 400, 250, and $40 \mathrm{~nm}$ were passivated with a silicon oxide layer whose thickness is, typically, $20 \%$ of that of the $\mathrm{Cu}$ film. A $15-\mathrm{nm}$-thick chromium interlayer is applied both between the $\mathrm{Cu}$ film and the substrate and between the $\mathrm{Cu}$ film and the passivation layer to serve as diffusion barrier. After thermally cycled to a stabilized condition, the $\mathrm{Cu}$ films showed columnar grains with an average grain size approximately equal to the film thickness. Many annealing twins and dislocations were also existent, as were shown in other studies of such films. ${ }^{7,12}$ In addition to the above specimens, 1000-nm-thick $\mathrm{Cu}$ films were also studied. The films were sputter deposited on oxidized silicon wafers and passivated with $50 \mathrm{~nm}$ silicon oxide. In this case, the interlayer is 50 nm-thick tantalum.

The curvature measurement technique that is routinely employed for measuring the thermomechanical response of thin films ${ }^{13,14}$ was employed for measuring stresses in the $\mathrm{Cu}$ film during thermal cycles between ambient temperature 


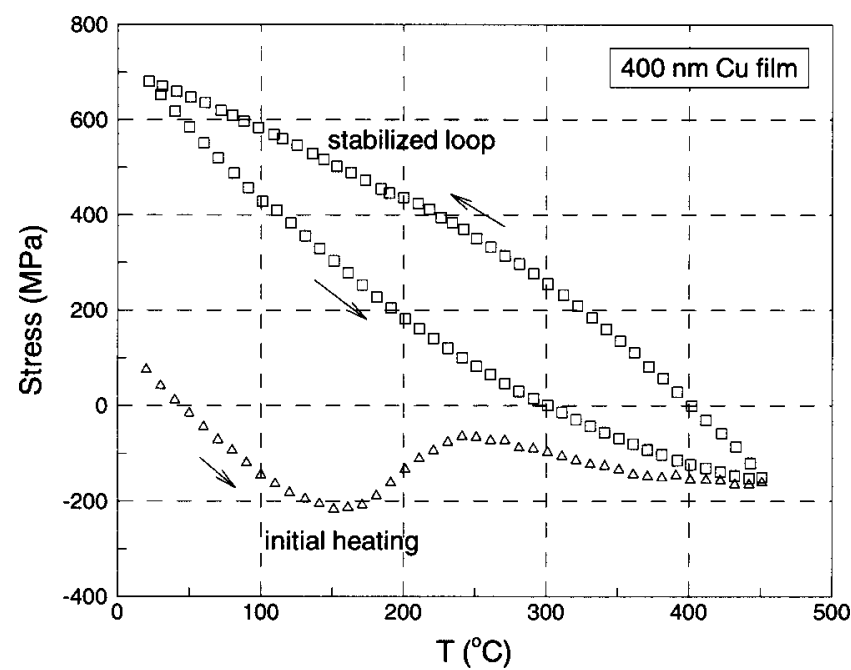

FIG. 1. Variation of stress in the passivated $400 \mathrm{~nm} \mathrm{Cu}$ film during thermal cycling.

(nominally, $20^{\circ} \mathrm{C}$ ) and $600{ }^{\circ} \mathrm{C}$. Unless otherwise stated, the nominal heating/cooling rate was maintained at $10^{\circ} \mathrm{C} / \mathrm{min}$. During the cooling phase of the thermal cycle and below $\sim 150{ }^{\circ} \mathrm{C}$, the prescribed cooling rate was maintained through the utilization of liquid nitrogen in the temperature control system. In selected cases, the temperature range was extended to subambient temperatures by interrupting the curvature measurement and slowly immersing the specimen in liquid nitrogen and then reheating to ambient followed by the resumption of subsequent measurements under controlled thermal cycles.

\section{RESULTS OF STRESS MEASUREMENT}

Figure 1 shows the variation of biaxial stress in the 400 $\mathrm{nm} \mathrm{Cu}$ film as a function of temperature between 20 and $450{ }^{\circ} \mathrm{C}$. The stress in the film, initially of tensile nature at ambient temperature, tends to be more compressive upon heating because of the constraint to thermal expansion of $\mathrm{Cu}$ imposed by the substrate that has a lower coefficient of thermal expansion vis a vis $\mathrm{Cu}$. During initial heating, however, a reduction in the magnitude of stress is seen from 150 to $250{ }^{\circ} \mathrm{C}$. This is due to the evolving microstructure, typified by grain growth. ${ }^{1,5}$ A stabilized response ensues upon subsequent cooling. Throughout the rest of this paper, only the stabilized thermomechanical response is discussed.

The initial slopes observed during heating and cooling define the elastic response of the $\mathrm{Cu}$ film. The deviation from the initial slope indicates plastic yielding. It is noted that, at elevated temperatures, the passivated $\mathrm{Cu}$ film can support reasonably large stresses. This is in sharp contrast with unpassivated $\mathrm{Cu}$ films which exhibit a significant stress relaxation at temperatures above $\sim 250{ }^{\circ} \mathrm{C} .{ }^{1-5,8}$ At room temperature, the passivated film can support a tensile stress close to $700 \mathrm{MPa}$ (Fig. 1).

An important feature observed in Fig. 1 is that, in a stabilized loop, yielding can commence at a "negative" stress. This is manifested by the heating curve that shows "com-

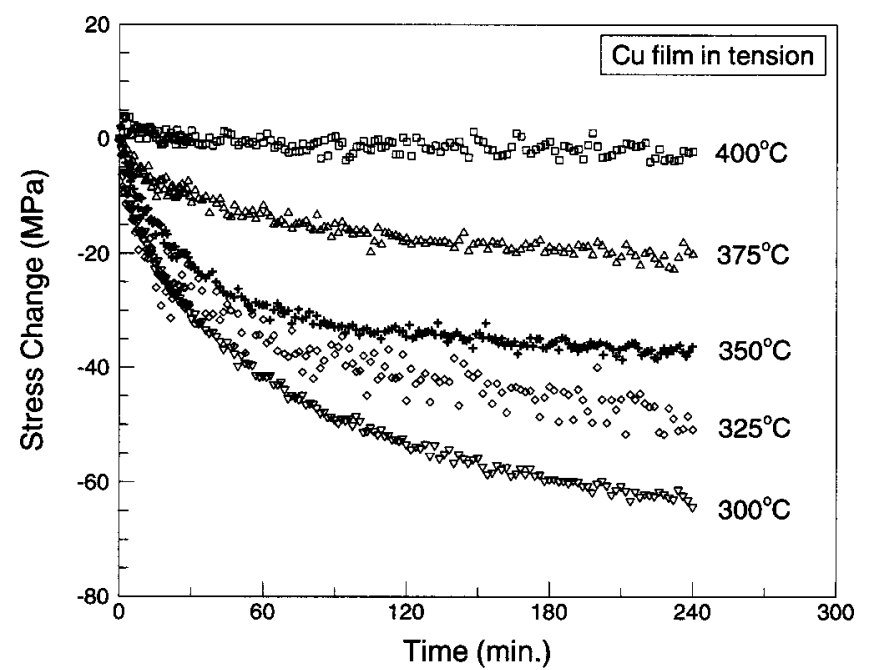

FIG. 2. Stress change as a function of time during isothermal hold. The beginning state was attained during cooling from $450^{\circ} \mathrm{C}$.

pressive" yielding at a tensile stress of about $175 \mathrm{MPa}$. The early yielding upon load reversal is generally referred to as Bauschinger effect in bulk metals. Qualitatively similar behavior has also been shown for passivated $\mathrm{Cu}$ films in other studies. ${ }^{1,2,5,8}$ Implications of this experimental feature in constructing the constitutive model will be discussed in Sec. IV.

In order to examine whether the highly asymmetric stress range about the zero axis (or equivalently, the very strong Bauschinger-like effect) observed in the stabilized loop in Fig. 1 was indeed the film's response and not an artifact of the methodology employed for measurement, passivated 400 $\mathrm{nm} \mathrm{Cu}$ films were thermally cycled between 20 and $450{ }^{\circ} \mathrm{C}$ to achieve stabilization and isothermally held at various temperatures during the cooling phase. The results are shown in Fig. 2 in the form of change in stress as a function of time. At 300 to $375^{\circ} \mathrm{C}$, significant stress relaxation can be seen over a period of $4 \mathrm{~h}$. However, at $400^{\circ} \mathrm{C}$ there is essentially no change in stress with time. This means that the stress in the $\mathrm{Cu}$ film is very close to zero at $400^{\circ} \mathrm{C}$, which is consistent with the cooling response shown in Fig. 1. As temperature decreases, stronger isothermal relaxation occurs (Fig. 2) owing to the increasing initial tensile stress (Fig. 1).

Figure 3 shows a comparison of stabilized stresstemperature response for passivated $\mathrm{Cu}$ films with thicknesses 400, 250, and $40 \mathrm{~nm}$. In all cases the Bauschinger-like effect is evident. It can be seen that the hysteresis becomes slightly smaller with decreasing film thickness, implying increasing difficulty of plastic deformation due to the dimensional constraint. At room temperature, a thinner film can support a higher tensile stress.

The $1000 \mathrm{~nm} \mathrm{Cu}$ films were subject to thermal cycles up to $600{ }^{\circ} \mathrm{C}$. A representative stress-temperature response is shown in Fig. 4. It is clear that there is no sign of stress relaxation for passivated $\mathrm{Cu}$ films even at $600{ }^{\circ} \mathrm{C}$ during continuous thermal excursions. An intermediate cycle is included in Fig. 4(a) for a temperature range of 20 to $300^{\circ} \mathrm{C}$ and in Fig. 4(b) for a range of 400 to $600{ }^{\circ} \mathrm{C}$. In contrast with the case of $\mathrm{Al}$ films where intermediate cycling near the 


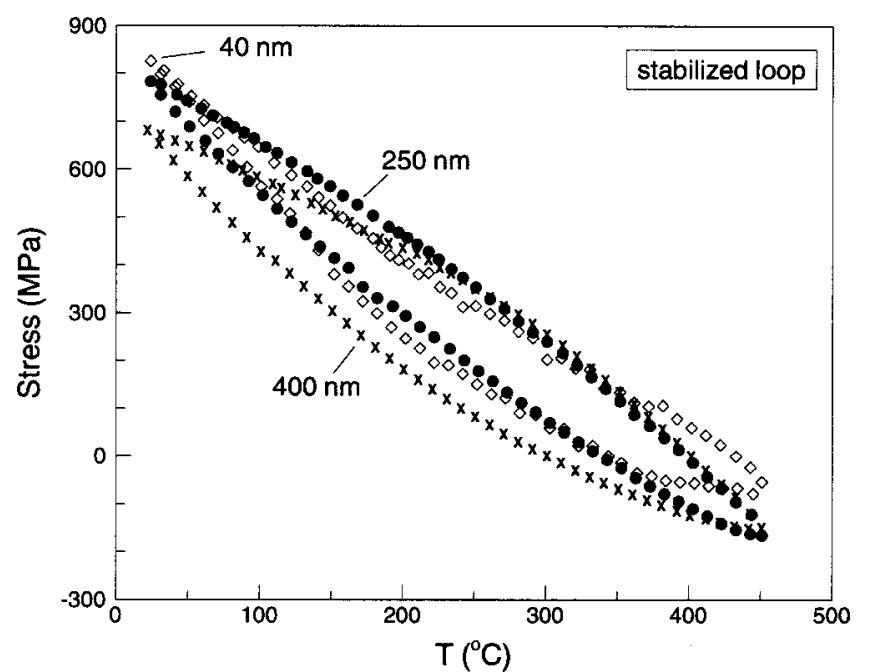

FIG. 3. Stabilized stress-temperature response for passivated $\mathrm{Cu}$ films of various thicknesses.

maximum temperature results in temporary cyclic hardening, ${ }^{15}$ the variation of thermal history shows essentially no effect on the overall stabilized stress-temperature response of passivated $\mathrm{Cu}$ films. In addition, the Bauschinger-like effect exists for all the loops in Fig. 4.

To further extend the temperature range considered above, a slow cooling to liquid nitrogen was conducted on the 400 $\mathrm{nm}$ film after cycled to stabilization between 20 and $450{ }^{\circ} \mathrm{C}$. The result is shown in Fig. 5. Although the curvature change at below room temperature was not monitored, linear extrapolation of the cooling to and reheating from $-196^{\circ} \mathrm{C}$ leads to a smooth connection of the measurable response, as evidenced by the model fit shown in Fig. 5 (to be discussed in the following section). Subsequent cycling between 20 and $450{ }^{\circ} \mathrm{C}$ shows a loop similar to those exhibited prior to the cryogenic excursion, suggesting that there is minimal effect of thermal history on the hysteresis. It is noticed from Fig. 5 that, upon reheating from liquid nitrogen, plastic yielding commences while the overall stress is still tensile.

In addition to the aforementioned experiments, the effect of heating/cooling rate on the evolution of stress was also investigated by varying the rate from 5 to $25^{\circ} \mathrm{C} / \mathrm{min}$. It is observed that the stress-temperature response is unaltered within the temperature range between 20 and $600{ }^{\circ} \mathrm{C}$. Therefore, within the range of the heating/cooling rate considered here, the rate-dependent effect is insignificant and therefore may be ignored for practical purposes. This is similar to the case of aluminum films. ${ }^{15}$

\section{CONSTRUCTION OF CONSTITUTIVE MODEL}

All the stress-temperature loops presented in Figs. 1, 3, 4, and 5, obtained from passivated $\mathrm{Cu}$ films with various thicknesses and under different temperature ranges, revealed the same qualitative features: rate-independent elastoplasticity with cyclic stabilization and Bauschinger-like phenomenon. Such a behavior cannot be represented, within the framework of continuum mechanics, by the elastic-perfectly plastic

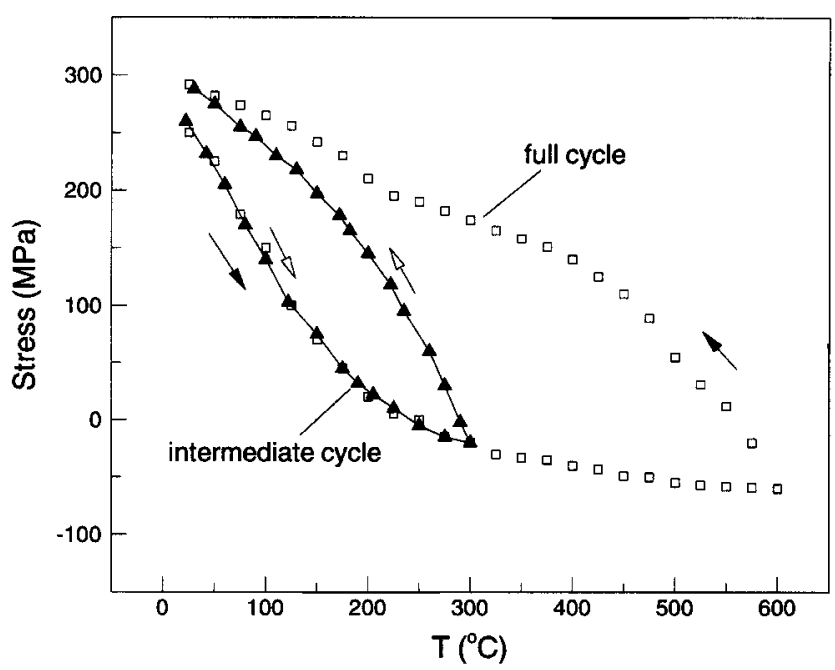

(a)

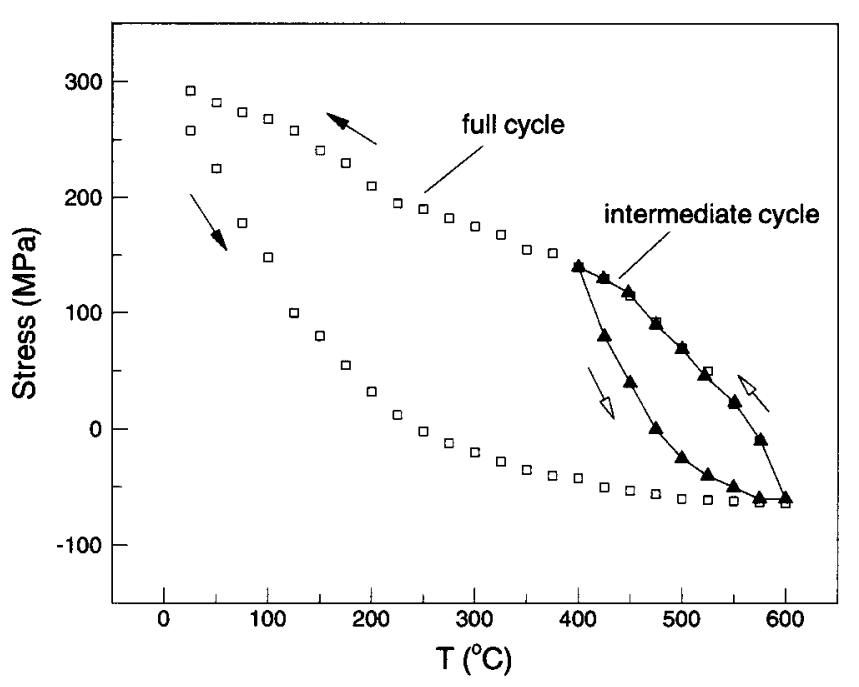

(b)

FIG. 4. Stress-temperature response of the $1000 \mathrm{~nm} \mathrm{Cu}$ film within the range of $20-600^{\circ} \mathrm{C}$. Different intermediate cycles are also shown in (a) and (b).

model with temperature-dependent yield strength such as in the case of $\mathrm{Al}$ films, because it will be impossible to endow the $\mathrm{Cu}$ film with a compressive yield strength that matches the heating response of the film at elevated temperatures. Necessarily, strain hardening has to be involved in the model for the films investigated in this work. However, typical isotropic hardening, with the yield surface in stress space expanding uniformly with no shape change or translation during deformation, ${ }^{16,17}$ is incompatible with the Bauschinger effect upon load reversal and predicts an eventual elastic shakedown without a hysteresis loop. Therefore, the isotropic hardening model cannot be applied to the $\mathrm{Cu}$ film. On the other hand, the classical kinematic hardening model, which assumes that the yield surface does not change its size and shape but simply translates in stress space in the direction of the outward normal, ${ }^{16,17}$ can be used to describe the stress evolution in $\mathrm{Cu}$ films. This is evident because the kinematic hardening model does indeed predict the existence of 


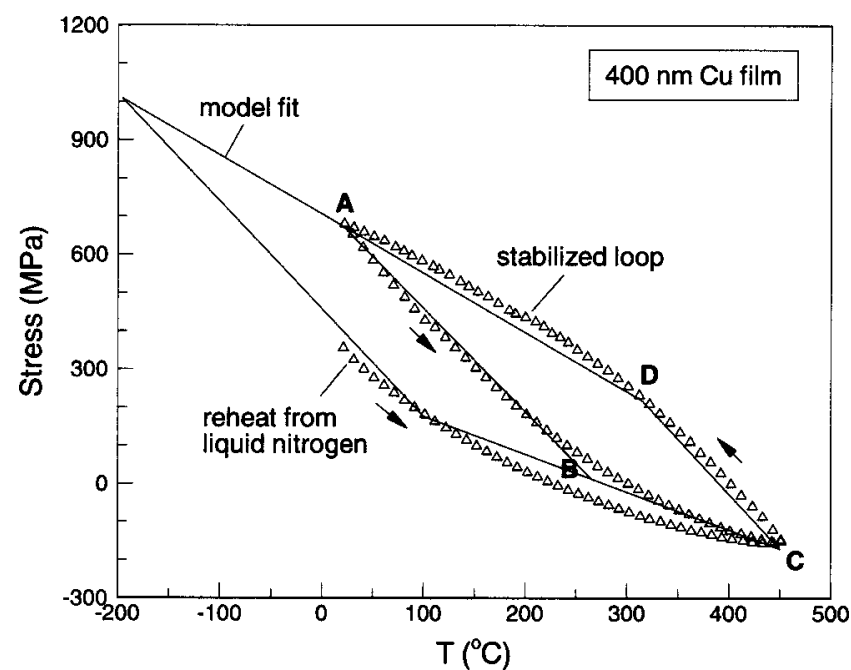

FIG. 5. Stress-temperature response of the $400 \mathrm{~nm} \mathrm{Cu}$ film, with the thermal cycling conducted extending to $-196^{\circ} \mathrm{C}$. Experimental data are fitted with the kinematic hardening model discussed in Sec. IV.

Bauschinger effect, and a steady state of alternating plastic deformation sets in after the first loading cycle, in full agreement with the experimental measurements reported in this article.

In the following, construction of a constitutive law of the passivated $\mathrm{Cu}$ film is sought by invoking the kinematic hardening model with linear hardening. The temperature dependence of yield strength is taken into consideration. In particular, a linear dependence of initial yield strength with temperature is employed,

$$
\sigma_{y}=\sigma_{0}\left(1-\frac{T}{T_{0}}\right)
$$

where $\sigma_{y}$ is the initial yield strength, $T$ is temperature, and $\sigma_{0}$ and $T_{0}$ are reference constants. Note that within the context of this formulation, the size of the yield surface will be a linear function of temperature but the essence of kinematic hardening, featuring a translating yield surface, is nevertheless preserved. For illustration purposes attention is devoted to the $400 \mathrm{~nm}$ film. The stabilized loop between 20 and $450^{\circ} \mathrm{C}$ is highlighted with four points in Fig. 5: $A$ and $C$ are the reversal points and $B$ and $D$ approximately define the transitions from elastic to plastic deformations. Since segments $A B$ and $C D$ represent the elastic behavior (the stress state traverses diagonally inside the yield surface), the two unknowns in Eq. (1), $\sigma_{0}$ and $T_{0}$, can then be determined by the following two equations:

$$
\begin{aligned}
& {\left[\sigma_{y}\right]_{A}+\left[\sigma_{y}\right]_{B}=\left|[\sigma]_{B}-[\sigma]_{A}\right|,} \\
& {\left[\sigma_{y}\right]_{C}+\left[\sigma_{y}\right]_{D}=\left|[\sigma]_{D}-[\sigma]_{C}\right|,}
\end{aligned}
$$

where $\left[\sigma_{y}\right]$ denotes the magnitude of yield strength at the specified temperature and $[\sigma]$ represents the stress value at the specified point obtained from the plot (Fig. 5). The hardening rate (or tangent modulus, defined to be the slope of the uniaxial stress-strain curve beyond yielding), then follows:

$$
\begin{aligned}
& H_{D \rightarrow A}=\frac{\left|[\sigma]_{A}-[\sigma]_{D}\right|-\left\{\left[\sigma_{y}\right]_{A}-\left[\sigma_{y}\right]_{D}\right\}}{\Delta \alpha \Delta T}, \\
& H_{B \rightarrow C}=\frac{\left|[\sigma]_{C}-[\sigma]_{B}\right|-\left\{\left[\sigma_{y}\right]_{B}-\left[\sigma_{y}\right]_{C}\right\}}{\Delta \alpha \Delta T},
\end{aligned}
$$

where $\Delta \alpha$ is the difference in coefficient of thermal expansion between $\mathrm{Cu}$ and the substrate, and $\Delta T$ is the temperature change involved. The solid curves shown in Fig. 5 are a result of the model with $\sigma_{0}=305 \mathrm{MPa}, T_{0}=1090 \mathrm{~K}$, and $H$ $=77 \mathrm{GPa}$. It satisfactorily fits the measured loop $A B C D$. With simple extrapolation to lower temperature, it can be seen that the model also matches the cryogenic thermal cycle remarkably well. (For reference, the thermoelastic properties of $\mathrm{Cu}$ at room temperature are: Young's modulus $110 \mathrm{GPa}$, Poisson's ratio 0.3 , and $\Delta \alpha=16.5 \times 10^{-6} \mathrm{~K}^{-1}$.)

The same methodology can be used to obtain the constitutive response of passivated $\mathrm{Cu}$ films with other thicknesses. In the above analysis, it is coincidental that the value $H$ is 77 GPa during both heating ( $B$ to $C$ ) and cooling ( $D$ to $A$ ). The constitutive law does not require the two hardening rates to be the same. Nevertheless, this hardening rate appears to be very high (greater than one half the magnitude of Young's modulus of $\mathrm{Cu}$ ). The strong hardening may be partially attributed to the small grains containing twin boundaries that can interact with dislocations and serve as additional barriers to slip. ${ }^{18}$ The concept of "back stress" normally associated with the kinematic hardening model may also be reasoned as such. More characterizations are necessary to establish a firm structure-property relation in such films. To this end, it is worth mentioning that the very strong hardening is not at much variance with the tensile stress-strain response of $\mathrm{Cu}$ films measured mechanically by Hommel et al. ${ }^{19}$ Within the tensile strain range of about 0.005 (approximately the same order as the thermally induced strain of interest here), the measured tangent modulus was reported to be only moderately smaller than the apparent Young's modulus.

\section{MODELING STRESSES IN Cu INTERCONNECTS}

One important purpose of developing the constitutive law based on experiments is to utilize it to numerically predict the thermal stress generated in $\mathrm{Cu}$ interconnect lines. To a first approximation the encapsulated line can be assumed to have the same properties as the passivated film. In this section, finite element analyses of an interconnect system, featuring $\mathrm{Cu}$ lines and a low dielectric constant material, are presented to illustrate the importance of choosing appropriate constitutive behavior in the modeling.

For the above-mentioned purpose, a series of parallel $\mathrm{Cu}$ lines, embedded within the dielectric on top of the silicon (Si) substrate, are considered. The metal lines are perpendicular to the paper. Because of the periodicity and symmetry in the lateral (across-the-line) direction, only one half of a unit segment is required in the calculation, as shown in Fig. 6. In the model $w$ and $h$ were both taken to be $400 \mathrm{~nm}$, and a full Si substrate thickness of $500 \mu \mathrm{m}$ was included. (The exact substrate thickness will not affect the modeling result if 


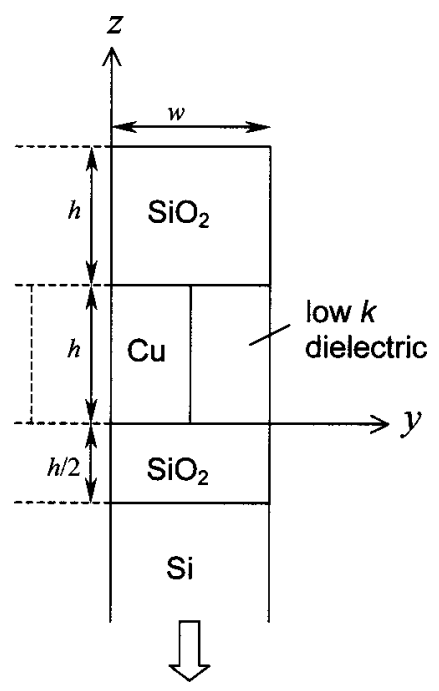

FIG. 6. Schematic of the interconnect structure used in the numerical modeling.

it is greater than about $100 \mu \mathrm{m}$ in the present case.) For simplicity the thin diffusion barrier layers between $\mathrm{Cu}$ and the surrounding material were not included. The dielectric arrangement follows an embedded scheme $e^{20,21}$ such that in between the metal lines a polymer based low-dielectric constant (low- $k$ ) material is used and conventional silicon oxide $\left(\mathrm{SiO}_{2}\right)$ exists directly above and below the metal/low- $k$ dielectric layer. The width of the $\mathrm{Cu}$ line and low- $k$ dielectric is taken to be the same.

In all calculations, attention was confined to deformations that preserve the mirror symmetry of the array. At the reference point $(y=0, z=0)$, the displacements along the $y$ and $z$ directions are taken to be zero. Along the symmetry axis, $y$ $=0$, the displacement in the $y$ direction vanishes. The other symmetry axis, i.e., the right boundary, is free to move but is forced to remain straight. All other boundaries are not constrained during deformation. The finite element program ABAQUS (Ref. 22) was used for the calculation. The discretizations used linear quadrilateral elements. The conver- gence of results was checked through various degrees of mesh refinement. The result presented in this paper is from calculations using a total of 1440 elements. A generalized plane strain formulation was used. This is an extension of the plane strain framework (with the $y z$ plane being the plane of deformation), achieved by superimposing a longitudinal normal strain along the line $(x)$ direction on the plane strain state. The generalized plane strain model is capable of yielding more realistic field quantities than the strict plane strain formulation. ${ }^{23}$ Such type of model has been used to calculate thermal stresses in single- and multilevel $\mathrm{Al}$ interconnects ${ }^{24-27}$ and compared favorably with the full three-dimensional analysis. ${ }^{28,29}$

The evolution of thermal stresses was modeled by imposing a spatially uniform temperature change from the initial stress-free temperature of $350^{\circ} \mathrm{C}$ (presumably, the film annealing temperature) to $20^{\circ} \mathrm{C}$. The $\mathrm{SiO}_{2}, \mathrm{Si}$, and low- $k$ dielectric phases were taken to be isotropic linear elastic solids. The material properties, extracted from Refs. 21, 23, and 24, used in the analysis are listed in Table I. The properties of the low- $k$ dielectric followed those of divinyl-siloxane-bisbenzocyclobutene reported in Ref. 21. Two constitutive behaviors for $\mathrm{Cu}$ are considered: the presently obtained elastic-plastic response with kinematic hardening (described in Sec. IV) and an elastic-perfectly plastic model, which fits the cooling portion of the loop in Fig. 5. Although $\mathrm{Cu}$ crystals are mechanically anisotropic, the direction dependence and texture effects were ignored because the present modeling serves as a straightforward illustration of comparisons of two simple constitutive behaviors. The thermoelastic properties of $\mathrm{Cu}$ are listed in Table I. The plastic response of the kinematic hardening model is given by Eqs. (1), (4), and (5) with the parameters $\sigma_{0}=305 \mathrm{MPa}, T_{0}=1090 \mathrm{~K}$, and $H$ $=77 \mathrm{GPa}$ (see the discussion in Sec. IV). The temperaturedependent yield strength for the perfectly plastic model, in accordance with the stress-temperature response during cooling (Fig. 5), is given in Table I. It is noted that the latter model is typically adopted for modeling stresses in $\mathrm{Al}$ interconnects ${ }^{24-32}$ and on occasion for $\mathrm{Cu} ;{ }^{33}$ we show below

TABLE I. Material properties used in the numerical analysis. E: Young's modulus, $\nu$ : Poisson's ratio, $\alpha$ : coefficient of thermal expansion (CTE), and $\sigma_{y}$ : yield strength. Unless otherwise stated, a linear variation of properties with temperature between the indicated temperatures is assumed.

\begin{tabular}{lrcccc}
\hline \hline & & $\mathrm{Cu}$ & $\mathrm{SiO}_{2}$ & $\mathrm{Si}$ & Low- $k$ dielectric \\
\hline$E(\mathrm{GPa})$ at & $20^{\circ} \mathrm{C}$ & 110 & 71.4 & 130.0 & 2.5 \\
& $350^{\circ} \mathrm{C}$ & 104 & 71.4 & 130.0 & $0.3^{\mathrm{a}}$ \\
$\nu$ at & $20^{\circ} \mathrm{C}$ & 0.3 & 0.16 & 0.28 & 0.34 \\
& $350^{\circ} \mathrm{C}$ & 0.3 & 0.16 & 0.28 & 0.34 \\
$\alpha\left(10^{-6} / \mathrm{K}\right)$ at & $20^{\circ} \mathrm{C}$ & 17.0 & 0.52 & 3.1 & 63.6 \\
& $350^{\circ} \mathrm{C}$ & 19.3 & 0.68 & 4.4 & 63.6 \\
$\sigma_{y}(\mathrm{MPa})^{\mathrm{b}}$ at & $20^{\circ} \mathrm{C}$ & 676 & $\ldots$ & $\ldots$ & $\ldots$ \\
& $350^{\circ} \mathrm{C}$ & 165 & $\ldots$ & $\ldots$ & $\ldots$ \\
\hline \hline
\end{tabular}

$\bar{~}{ }^{a}$ Linear variation only between 20 and $180^{\circ} \mathrm{C}$ (see Ref. 21$)$; a constant value $(0.3 \mathrm{GPa})$ between 180 and $350{ }^{\circ} \mathrm{C}$.

${ }^{\mathrm{b}}$ For the elastic-perfectly plastic model only. The kinematic hardening model is described by Eqs. (1), (4), and (5) with $\sigma_{0}=305 \mathrm{MPa}, T_{0}=1090 \mathrm{~K}$, and $H=77 \mathrm{GPa}$ (see Sec. IV for details). 


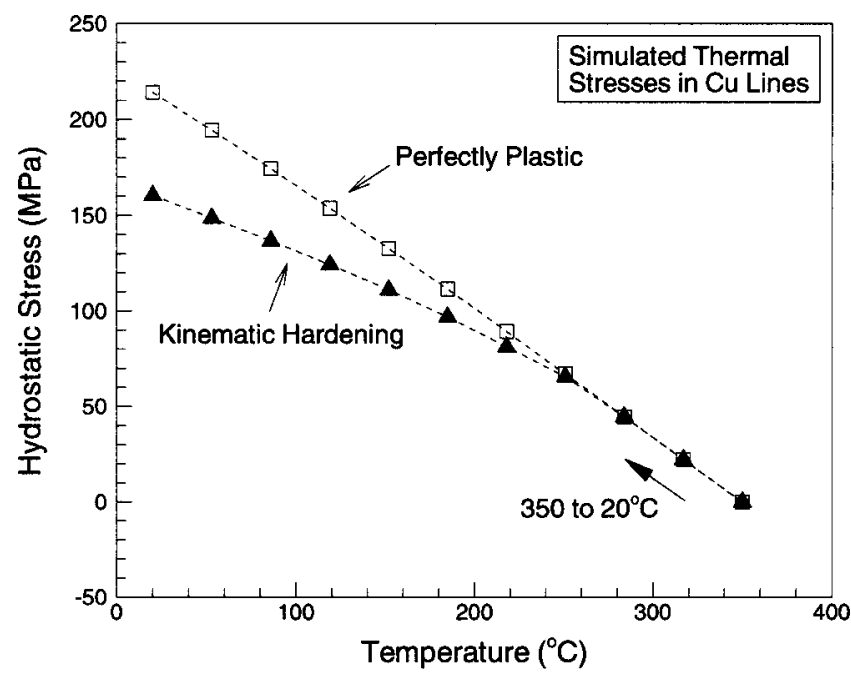

FIG. 7. Calculated variation of hydrostatic stress in the $\mathrm{Cu}$ line with temperature using the kinematic hardening model and the perfectly plastic model.

that this choice can lead to a large error in the case of $\mathrm{Cu}$.

Figure 7 shows the evolution of hydrostatic stress, defined as $\frac{1}{3}\left(\sigma_{x x}+\sigma_{y y}+\sigma_{z z}\right)$, as a function of temperature during cooling from 350 to $20^{\circ} \mathrm{C}$. The stress magnitude is averaged over the cross section of the interconnect. Both the kinematic hardening model and the perfectly plastic model are included in Fig. 7. It is seen that a significant difference develops when the temperature is below about $200{ }^{\circ} \mathrm{C}$. The fact that the perfectly plastic model predicts a tensile stress higher than that of the kinematic hardening model is because a much steeper increase in yield strength with temperature in the former has to be imposed to match the measured cooling curve in Fig. 5. As a consequence, if one accepts the result on the basis of the experimentally determined kinematic hardening response for the $\mathrm{Cu}$ film, the perfectly plastic model shows an error in stress as large as $40 \%$ upon cooling to room temperature. This illustrates the importance of applying the appropriate constitutive response in modeling interconnect stresses.

Figure 8 shows the evolution of averaged equivalent plastic strain in the $\mathrm{Cu}$ line during cooling from 350 to $20^{\circ} \mathrm{C}$. Although the continuum approach is used in the present case of submicron material dimension, salient insights of the deformation process can still be obtained. In the present case, the equivalent plastic strain signifies the extent of irrecoverable deformation and the associated crystal defects. The perfectly plastic model predicts essentially no plasticity in $\mathrm{Cu}$ except close to room temperature. The kinematic hardening model, however, shows significant plasticity developed after an initial elastic response. The accumulation of plastic strain, given by the kinematic hardening model, is in line with the "back stress" concept observed in the passivated $\mathrm{Cu}$ films discussed in Sec. IV. The incorporation of the lateral low- $k$ dielectric, with a very low modulus and very high coefficient of thermal expansion compared with both $\mathrm{Cu}$ and $\mathrm{SiO}_{2}$, is known to suppress hydrostatic tension and enhance plastic

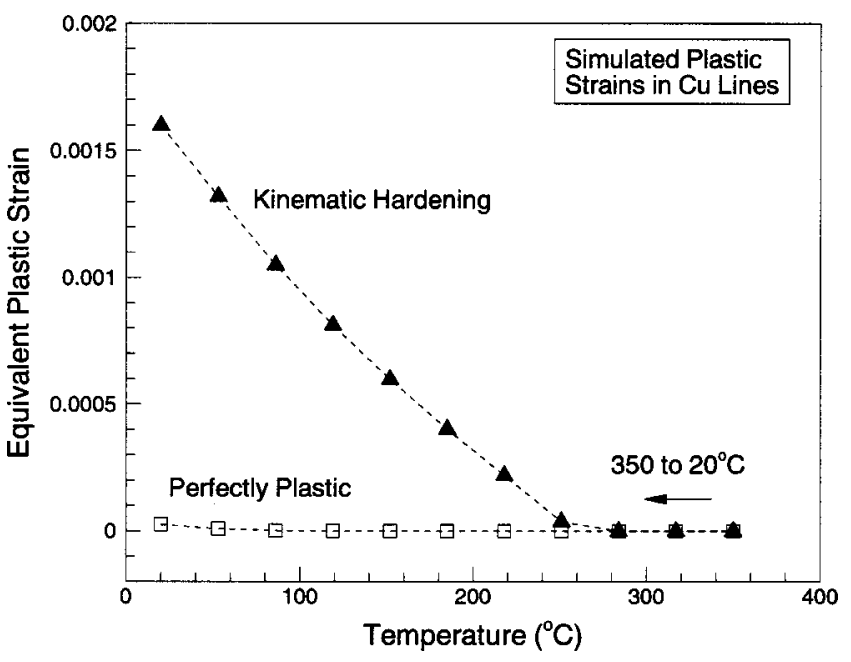

FIG. 8. Calculated variation of equivalent plastic strain in the $\mathrm{Cu}$ line with temperature using the kinematic hardening model and the perfectly plastic model.

deformation in the embedded $\mathrm{Cu}$ line. This feature cannot be captured by the perfectly plastic model.

\section{CONCLUSIONS}

The generation of thermal stresses in passivated $\mathrm{Cu}$ films with various thicknesses and thermal cycling histories was measured. The stress does not relax at elevated temperatures during the temperature cycle. The film does not show any rate-dependent effect over a range of heating/cooling rate from 5 to $25^{\circ} \mathrm{C} / \mathrm{min}$. An elastic-plastic model with kinematic strain hardening has to be employed to fit the experimental results showing a stabilized loop and the Bauschinger-like effect. This is drastically different from the unpassivated and passivated $\mathrm{Al}$ films and the unpassivated $\mathrm{Cu}$ films. The procedures of extracting the temperature dependent properties are presented. The film shows very high strain hardening beyond the elastic limit. It was also found that, with the inclusion of intermediate cycles within the stabilized loop and cryogenic excursion, there is minimal effect of thermal history on the already established hysteresis. The importance of utilizing an appropriate constitutive response in predicting thermal stresses in $\mathrm{Cu}$ interconnects was illustrated with finite element modeling. Treating $\mathrm{Cu}$ as an elastic-perfectly plastic solid with temperature dependent yield strength results in significant errors in the stress and strain developed inside the $\mathrm{Cu}$ line.

\section{ACKNOWLEDGMENTS}

This work is partially supported by National Science Foundation under Grant No. CMS-9874742. The assistance of P. V. S. N. Lalitavarma and A. Bagchi in conducting some experiments reported in this work is acknowledged.

${ }^{1}$ R. P. Vinci, E. M. Zeilinski, and J. C. Bravman, Thin Solid Films 262, 142 (1995).

${ }^{2}$ M. D. Thouless, K. P. Rodbell, and C. Cabral, Jr., J. Vac. Sci. Technol. A 14, 2454 (1996). 
${ }^{3}$ P. A. Flinn, J. Mater. Res. 6, 1498 (1991).

${ }^{4}$ M. D. Thouless, J. Gupta, and J. M. E. Harper, J. Mater. Res. 8, 1845 (1993).

${ }^{5}$ S. P. Baker, A. Kretschmann, and E. Arzt, Acta Mater. 49, 2145 (2001).

${ }^{6}$ D. Weiss, H. Gao, and E. Arzt, Acta Mater. 49, 2395 (2001).

${ }^{7}$ Y.-L. Shen, S. Suresh, M. Y. He, A. Bagchi, O. Kienzle, M. Ruhle, and A. G. Evans, J. Mater. Res. 13, 1928 (1998).

${ }^{8}$ R. M. Keller, S. P. Baker, and E. Arzt, J. Mater. Res. 13, 1307 (1998).

${ }^{9}$ G. Dehm, D. Weiss, and E. Arzt, Mater. Sci. Eng., A 309-310, 468 (2001).

${ }^{10}$ V. Weihnacht and W. Bruckner, Acta Mater. 49, 2365 (2001).

${ }^{11}$ J. M. E. Harper, C. Cabral, P. C. Andricacos, L. Gignac, I. C. Noyan, K. P. Rodbell, and C. K. Hu, J. Appl. Phys. 86, 2516 (1999).

${ }^{12}$ M. Hommel and O. Kraft, Acta Mater. 49, 3935 (2001).

${ }^{13}$ W. D. Nix, Metall. Trans. A 20A, 2217 (1989).

${ }^{14}$ P. A. Flinn, D. S. Gardner, and W. D. Nix, IEEE Trans. Electron Devices ED-34, 689 (1987).

${ }^{15}$ Y.-L. Shen and S. Suresh, Acta Metall. Mater. 43, 3915 (1995).

${ }^{16}$ A. Mendelson, Plasticity: Theory and Application (MacMillan, New York, 1968), p. 94.

${ }^{17}$ S. Suresh, Fatigue of Materials, 2nd ed. (Cambridge University Press, Cambridge, U.K., 1998), p. 25.
${ }^{18}$ J. P. Hirth and J. Lothe, Theory of Dislocations, 2nd ed. (WileyInterscience, New York, 1982), p. 831.

${ }^{19}$ M. Hommel, O. Kraft, and E. Arzt, J. Mater. Res. 14, 2372 (1999).

${ }^{20}$ Y.-L. Shen, J. Vac. Sci. Technol. B 17, 2115 (1999).

${ }^{21}$ J.-K. Zhao, W.-J. Qi, and P. S. Ho, Microelectron. Reliab. 42, 27 (2002).

${ }^{22}$ ABAQUS, Version 6.1 (Hibbit, Karlson and Sorensen, Pawtucket, RI, 2000).

${ }^{23}$ Y.-L. Shen, S. Suresh, and I. A. Blech, J. Appl. Phys. 80, 1388 (1996).

${ }^{24}$ Y.-L. Shen, J. Mater. Res. 12, 2219 (1997).

${ }^{25}$ Y.-L. Shen, J. Appl. Phys. 82, 1578 (1997).

${ }^{26}$ A. Gouldstone, Y.-L. Shen, S. Suresh, and C. V. Thompson, J. Mater. Res. 13, 1956 (1998).

${ }^{27}$ M. S. Kilijanski and Y.-L. Shen, Microelectron. Reliab. 42, 259 (2002).

${ }^{28}$ Y.-L. Shen, J. Appl. Phys. 84, 5525 (1998).

${ }^{29}$ Y.-L. Shen and Y. L. Guo, J. Vac. Sci. Technol. B 17, 448 (1999).

${ }^{30}$ A. I. Sauter and W. D. Nix, IEEE Trans. Compon., Hybrids, Manuf. Technol. 15, 594 (1992).

${ }^{31}$ J. Lee and A. S. Mack, IEEE Trans. Semicond. Manuf. 11, 458 (1998).

${ }^{32}$ L. T. Shi and K. N. Tu, J. Appl. Phys. 77, 3037 (1995).

${ }^{33}$ T. Marieb, A. S. Mack, N. Cox, D. Gardner, and X. C. Mu, Mater. Res. Soc. Symp. Proc. 403, 639 (1996). 